\title{
Developing and Validating a Competence Framework for Secondary Mathematics Student Teachers through a Delphi Method
}

Laura Muñiz-Rodríguez $^{\mathrm{a}, \mathrm{c}}$, Pedro Alonso ${ }^{\mathrm{b}}$, Luis J. Rodríguez-Muñiz ${ }^{\mathrm{a}}$, Martin Valcke ${ }^{\mathrm{c}}$

${ }^{a}$ Department of Statistics and Operational Research and Mathematics Didactics,

University of Oviedo, c/ Calvo Sotelo, s/n, 33007, Oviedo, Asturias, Spain

${ }^{b}$ Department of Mathematics, University of Oviedo, c/ Calvo Sotelo, s/n, 33007,

Oviedo, Asturias, Spain

${ }^{c}$ Department of Educational Studies, Ghent University, Henri Dunantlaan, 2, 9000,

Gent, Belgium

Corresponding author: Laura Muñiz-Rodríguez. Department of Statistics and

Operational Research and Mathematics Education, University of Oviedo, c/ Calvo

Sotelo, s/n, 33007, Oviedo, Asturias, Spain. E-mail address: uo205132@uniovi.es 


\section{Developing and Validating a Competence Framework for Secondary}

\section{Mathematics Student Teachers through a Delphi Method}

Initial teacher education programmes provide student teachers with the desired competences to develop themselves as teachers. Although a generic framework for teaching competences is available covering all school subjects in Spain, the initial teacher education programmes curriculum does not specify which competences secondary mathematics student teachers should acquire during their initial teacher education. This explains why this study aimed at developing and validating a competence framework for secondary mathematics student teachers in Spain. Building on existing models and international frameworks, a preliminary list of competences was drawn up. The validation process was based on a Delphi method. Besides experts expressed their opinions about the formulation of the chosen competences. A comprehensive framework of thirtythree competences for secondary mathematics student teachers could be validated.

Keywords: competences for teaching; Delphi method; initial teacher education programmes; secondary mathematics teacher education

\section{Introduction}

Worldwide, teacher education institutions struggle to define core teaching competences in view of the accreditation of initial teacher education programmes and resulting diplomas. However, there is hardly any international consensus about which competences student teachers should master after completing the initial teacher education. It is, however, an important question to be addressed, taking into account the relevance of training qualified teachers to ensure high-quality student learning outcomes 
(Hill, Rowan, \& Ball, 2005; Kleinhenz \& Ingvarson, 2007).

In Spain, the initial teacher education for specialist teachers is based on a professional master degree on teacher training, expected to provide student teachers with the theoretical and practical competences necessary for the profession. However, since its implementation in the academic year 2009/2010, this programme has received critiques from student teachers, teacher educators, educational policymakers and teacher education researchers. Recent research points at the critical need for specific competences attending the capacities of secondary mathematics student teachers (Comisión de Educación de CEMAT, 2011; Muñiz-Rodríguez et al., 2016; Santos \& Lorenzo, 2015).

In particular, the related master degree does not specify which professional knowledge, skills and attitudes specialist student teachers should acquire. The national education curriculum only contains general guidelines as to the competences required for the accreditation of initial teacher education programmes (Ministerio de Educación y Ciencia, 2007). Specific competences fitting the specifics of specialist fields such as mathematics, are lacking. Spain is not an exception in this context. According to the OECD (2005), in countries where the teaching profession follows a career-based system and teachers are generally expected to stay in the public sector employment throughout their working life, entry criteria do hardly emphasise student teachers' competences.

In recent years, research about competences for secondary mathematics student teachers has increased. However, up to now no operational proposals are available in the Spanish context. This explains why national mathematics teacher education associations keep stressing the need for the development, application and assessment of a framework of specific competences for secondary mathematics student teachers at the national level (Comisión de Educación de CEMAT, 2011; Santos \& Lorenzo, 2015). In 
the international mathematics related arena, significant input is available at the primary education level (Alake-Tuenter et al., 2013; Tang, Cheng, \& Wong, 2016) and the secondary education level (Australian Association of Mathematics Teachers, 2006; National Council of Teachers of Mathematics, 2012). The present research addresses this specific call for the definition and validation of a competence framework for secondary mathematics student teachers in Spain. Our focus on this particular group is inspired by a number of facts. Firstly, mathematics is considered a critical domain in secondary education, especially due to a lack of this type of specialist teachers (Parveva et al., 2011). Secondly, mathematics is linked to the critical STEM domain for which worldwide - research asks to pay more attention to. The role of teachers is considered to be important in this context. Lastly, the development of teaching competences in this particular knowledge domain is pioneering curriculum work in Spain.

The present study pursued a twofold goal. On the one hand, we aimed at designing a comprehensive framework of professional competences for secondary mathematics student teachers in Spain. On the other hand, we tried to validate this framework through an expert panel consultation method. This method aimed at reaching, as far as possible, a consensus about the core competences to be acquired by secondary mathematics student teachers during an initial teacher education programme.

This paper is organised in four main sections. To begin with, the theoretical base supporting this research is described. Next, the methodology used for the validation of the competence framework is explained. The Delphi method consisting of an online survey with experts in the fields of mathematics, psychology, education and mathematics education was employed. This section includes the rationale of the method, information about the sample, the development of the three rounds of the consultation process, and a description of the instrument used in each round. Next, the results 
obtained from the data analysis are presented. The article ends with a discussion of the results and the implications of this study.

\section{Theoretical Foundations}

The adoption of competence-based systems in initial teacher training has increased all over the world. The concept of competence in teaching, refers to the combination of knowledge, skills and attitudes that enables teachers to develop effective teaching practice at multiple levels: the individual teacher, the school environment, the educational system, educational authorities, and beyond (European Commission, 2013). A set of competences leads to the compilation of a competence framework.

In the literature, we observe a conceptual confusion between competences and standards (Reynolds, 1999). Standards build on a comprehensive competence framework by also providing benchmark information on effective practice. In some countries, initial teacher education institutions have already moved forward to the development of national standards for the accreditation of teachers, but other countries, as Spain, are still defining the previous competence framework. Standards are more oriented to the quality assessment of teaching and learning.

The existence of comprehensive and structured frameworks of professional teaching competences has important practical implications. A competence framework defines which proficiency levels student teachers should achieve and strengthen during their educational process. They can therefore be employed as reference points for developing initial teacher education programmes and guiding curriculum development (Erebus International, 2008; Morris, Hiebert, \& Spitzer, 2009). Besides, they provide clear, long-term goals for teachers' learning and professional growth (Kleinhenz \& Ingvarson, 2007), and - together with benchmark levels - serve as measures to assess 
the quality of teaching (European Commission, 2013).

Kleinhenz and Ingvarson (2007) established three essential steps in developing teaching competences and professional standards: to define what is to be measured (i.e., competences), to decide how teaching should be measured, and to identify what counts as meeting the standards (i.e., benchmark information). So, a first step in our research

led to determine what professional competences should secondary mathematics student teachers develop during initial teacher education. This study started from two theoretical frameworks: the Pedagogical Content Knowledge (PCK) model (Shulman, 1986) and the Technological Pedagogical Content Knowledge (TPACK) model (Mishra \& Koehler, 2006). Next, an international literature review on competences for teaching mathematics at the secondary education level was carried out building on these models. The overall process resulted in a preliminary framework of thirty-two competences.

\section{The TPACK Model}

In the literature, teachers' knowledge and competences for teaching can be defined on the basis of different theoretical models. A widespread approach is named the Technological Pedagogical Content Knowledge model (TPACK). It builds on the intersection of three sources of knowledge: content $(\mathrm{C})$, pedagogy $(\mathrm{P})$ and technology (T). As such it represents a multi-dimensional perspective on critical teaching competences and prevents adopting an additive approach defining a competence framework.

The PCK model results from Shulman's (1986) distinction between three categories of teaching knowledge: the content knowledge (CK), the pedagogical knowledge (PK), and the intersection of content and pedagogy, known as pedagogical content knowledge (PCK). Subsequently, he extended his model including four 
additional categories: curriculum knowledge, knowledge of learners and their characteristics, knowledge of educational contexts, and knowledge of educational ends, purposes and values and their philosophical and historical grounds.

More recently, Mishra and Koehler (2006) expanded the PCK model with a technology $(\mathrm{T})$ dimension. In doing so, seven domains of knowledge, from which teaching competences may be organised, could be demarcated (see Figure 1). This led to the construction of the TPACK model.

[Figure 1 near here]

Many implications of this theory are discussed in the literature in relation to: conceptualizing teachers' professional knowledge in practice - for instance, in mathematics (Hill, Ball, \& Schilling, 2008) -, curriculum development (Papanikolaou, Gouli, \& Makri, 2014), learning environment design (Doering et al., 2009), or teaching assessment (Hansen, Mavrikis, \& Geraniou, 2016). However, other authors remain reluctant, identifying signs of weakness in this model (Dalziel \& Dobozy, 2016; Kimmons, 2015).

Beyond these domains of knowledge, Shulman (1987) linked to his model a set of processes that (student) teachers are supposed to adopt in view of effective teaching. This cycle, named 'model of pedagogical reasoning and action', builds upon five core competences (see Figure 2).

[Figure 2 near here]

Both models, the TPACK and the pedagogical reasoning and action model, helped building the first layer in the development of a competence framework for secondary mathematics student teachers in view of this study. 


\section{An International Overview of Teaching Competences and Professional}

\section{Standards}

A search of the academic literature including teacher education organisations in a set of countries - the United States (US), Australia, the United Kingdom (UK), Germany, and the Asia-Pacific region - was carried out in order to develop a second layer of our competence framework. Different approaches have been developed in many countries around the world that could serve as models for the design of a framework within the Spanish context, where at this moment no common ground exists at the competence level. Because some national initial teacher training institutions have already moved forward from teaching competences to professional standards, this literature review sometimes refers to national standard frameworks. In such cases, the analysis was carried out only at the competence level. Although our attention focused on competences for the teaching of mathematics, also generic core competences for student teachers were considered. This is because specialist teachers must be qualified not only in a subject knowledge domain, but also in relation to general core competences.

The National Council for the Accreditation of Teacher Education (NCATE) is a coalition of organisations of teachers, teacher educators, professional content specialists, and policymakers, committed to quality teaching within the US. The main goal of the NCATE is to assure that graduates of accredited institutions acquire the knowledge, skills, and dispositions necessary for effective teaching. The NCATE developed a framework of competences put forward as standards and reviewed every seven years, which describes the specialised content that teacher candidates should master (National Council for the Accreditation of Teacher Education, 2008). Each competence is associated with a rubric describing different performance levels. 
Nowadays, nearly all the US states have adopted the NCATE's professional standards for the accreditation of teacher education programmes.

The NCATE deals with a variety of disciplines, including mathematics. Through the Council of the Accreditation of Educator Preparation (CAEP), the National Council of Teachers of Mathematics (NCTM) was one of the first subject-specific organisations responsible for setting teaching competences and professional standards in the mathematics field in the US context. The NCTM CAEP Standards provide a guide to institutions to design initial education programmes for prospective mathematics teachers at elementary, middle-grade and secondary education level (National Council of Teachers of Mathematics, 2012). The NCTM CAEP Standards largely fits the TPACK model in the field of mathematics teacher education. However, the technology dimension is not sufficiently represented.

Still under the NCATE's umbrella, the International Society for Technology in Education (ISTE) established a framework of competences and performance indicators for teachers of the digital age in the US context (International Society for Technology in Education, 2008). According to these competences, at the completion of an initial teacher education programme student teachers must (a) use technology to facilitate and inspire students' learning and creativity, (b) design and develop digital age learning experiences and assessments, (c) model digital age work and learning, (d) promote and model digital citizenship and responsibility, and (e) engage in professional growth and leadership. These technological competences were taken into account in our study.

Parallel to the NCATE's programme but in another geographic area, the Australian Association of Mathematics Teachers (AAMT) is a federation of associations of mathematics teachers from all Australian states aiming at supporting the teaching profession and promoting mathematics learning. The AAMT has developed a 
range of competences which reflects a national consensus about the knowledge, skills and attributes required for teaching mathematics (Australian Association of Mathematics Teacher, 2006). Taken as a whole, these competences provide a framework for teachers' initial education and professional growth.

In the UK, four national agencies are responsible for the education and development of teachers and the improvement of teaching quality: the Teaching Agency (TA) in England - formerly the General Teaching Council for England (GTCE), the General Teaching Council for Scotland (GTCS) in Scotland, the General Teaching Council for Wales (GTCW) in Wales - renamed as the Education Workforce Council (EWC), and the General Teaching Council for Northern Ireland (GTCNI) in Northern Ireland. All of them set out competences defining what a trainee teacher must know, understand and be able to do to be accredited for the teaching profession (Department for Education, 2011; General Teaching Council for Northern Ireland, 2011; General Teaching Council for Scotland, 2012; Welsh Government, 2011).

In Germany, the 'Standards für die Lehrerbildung: Bildungswissenschaften' for teacher education, adopted in 2004 , define the requirements to be met by teachers (Lohmar \& Eckhardt, 2013). These requirements are generated by the competences aimed for. In terms of mathematics teacher education, the German COACTIV (Professional Competence of Teachers, Cognitively Activating Instruction, and Development of Students' Mathematical Literacy) project, was set up to investigate teacher competences as a key determinant of instructional quality in mathematics. Combining findings from various research perspectives, the COACTIV team proposed a theoretical model of teachers' professional competences and applied it to mathematics teachers (Baumert \& Kunter, 2006). 
In the broader Asia-Pacific region, the findings of a scoping study show that most countries in this region have developed or are developing teaching competences as a tool for guiding teacher education and teaching practice (Erebus International, 2008). For instance, the Ministry of Education of the People's Republic of China published in 2012 the National Professional Standards for K-12 Teachers (Wu, 2014). This document represents the first national set of competences for teachers in China and serves as a common framework of basic requirements for initial teacher education graduates in elementary and secondary education. On the other hand, the development of distinctive competences for mathematics is a recurrent issue in Sri Lanka and Korea.

\section{Methodology}

Pulling together the above theoretical basis and the international perspective, a preliminary competence framework for secondary mathematics student teachers was developed. To start with, a comprehensive list of competences was drawn up from all mentioned international frameworks. Competences were compared looking for commonalities and differences and classified by related domains. This helped to filter isolated or less relevant ideas. Overlapping competences were removed. Next, competences referring to similar concepts, skills, attitudes or values were combined. This process resulted in a preliminary list consisting of thirty-two competences, categorized into twelve clusters. This was the base to tackle the validation process through an expert panel consultation study, using the Delphi method.

\section{The Delphi Method}

The Delphi method consists of an iterative process during which a group of experts expresses their opinion on a particular subject to reach a consensus (Hsu \& Sandford, 
2007; Linstone \& Turoff, 1975). The Delphi method is a broadly used and accepted tool with a diverse range of applications in a wide variety of areas (Hsu \& Sandford, 2007; Linstone \& Turoff, 1975), including education (Green, 2014). In particular, the Delphi method has recently been adopted in the context of teacher education as a valuable tool to develop teaching competences for primary school teachers (Alake-Tuenter et al., 2013), to define quality indicators for teacher educators (Koster et al., 2005), or to integrate technology into teacher education (Volman, 2005).

The Delphi method - when focusing on e.g., the design of a questionnaire - can be summarised as follows (Linstone \& Turoff, 1975): a research group designs a questionnaire which is sent to a respondent group; after the questionnaire has been completed by participants, the research group analyses the data and, based on the results, develops a new version to be submitted to the - same or another - respondent group; the latter gets the opportunity to re-evaluate the original answers and modify their opinions according to the collective view of the group. The process is finished when consensus criteria are met.

Through a Delphi method, participants have the opportunity to reassess their initial judgement. As a result, original statements are changed or modified during consecutive rounds until convergence of opinions is achieved. Feedback is probably the most important element in a Delphi method and it is the driver of consensus development (Hsu \& Sandford, 2007). Anonymity among participants is to be used to reinforce the experts' self-concept (Linstone \& Turoff, 1975).

Several reasons justify the use of a Delphi method in this study. This research topic requires the dynamic of a consultation process, so that the final outcome must be viewed as a reflection of agreement on the experts' opinions. In this sense, the Delphi method is considered an effective and reliable tool (Linstone \& Turoff, 1975; Smith \& 
Simpson, 1995). In this study, an online Delphi approach was adopted, in which communication with experts, and questionnaire design, delivery and administration was accomplished through the Internet. The use of an online procedure provides additional benefits. For instance, it does not require the physical presence of participants, which is time-consuming and cost-ineffective, affecting the feasibility of the study. Through the online approach, participants chose in a flexible way their time and place to take part in the survey.

\section{Sample}

The Delphi method involved two groups: a monitor team and an expert panel. The monitor team consisted of the four authors of this research. They were responsible for the design, development and management of the Delphi method, i.e., selection of and communication with the expert panel, preparation of the materials, data collection, data analysis, and presentation of the results.

The expert panel involved two subgroups: A (21) and B (10). In the first round, experts from panel A participated. In subsequent rounds, both panels were involved. The incorporation of new members in the expert panel during subsequent rounds increases and ensures validity and reliability of the results until a consensus is achieved (Linstone \& Turoff, 1975). Of the 31 experts, 13 were female and 18 were male. Experts were sought to represent different and relevant backgrounds and fields: secondary mathematics teachers (7), university professors (21) - 6 in mathematics, 3 in psychology and/or education, 12 in mathematics education - and mathematics teaching technical advisors working in the ministry (3). These professors, teachers and practitioners with long and valuable experience (mean $=35.7$ years) were selected on the basis of literature search and monitor team's networks. A non-random convenience sampling technique was used. The criteria for selection were based on professional profile, experience and expertise in 
the field of mathematics teacher education or scientific publications. All experts were familiar with teacher education and teaching competences from both a theoretical and a practical perspective. Some of them had participated in curriculum design at the request of the Spanish ministry of education.

\section{Procedure, data collection and analysis}

According to Linstone and Turoff (1975), setting up three rounds is usually enough for a Delphi method approach. Further rounds hardly tend to result in further significant changes. In every round, an online questionnaire was sent to the expert panel, which took about fifteen minutes to complete. The instrument was modified for each subsequent round according to the results of the previous one. Instruments were designed and managed through the software LimeSurvey ${ }^{\circledR}$. In total, three rounds were set up. Analysis showed how ratings hardly changed during the third round, suggesting that a consensus was attained.

In the first-round instrument, participants were asked to rate the extent to which each competence was adequately defined in view of teaching mathematics at secondary education. A five-point Likert scale was used. Experts were invited to justify low ratings by proposing modifications in the wording of a competence definition. This helped to minimise redundancy and ambiguity in the formulation of competences and limit the number of rounds required to reach consensus. Experts were invited to add new teaching competences if deemed necessary. Results from round one were next scrutinised by the monitor team and presented to the expert panel in round two.

The second round of the Delphi method started with an adaptation of the initial competence framework based on results from round one. Participants were asked to rate the adequacy of modified competences that did not reflect a consensus after the first 
round. In addition, experts were asked to indicate whether they agreed or disagreed with the addition of three new competences resulting from the former round. In view of this, an alternative five-point Likert scale was used. Results from round two were used to design the third-round instrument.

In the third and last round, the focus was again on competences not reflecting any consensus thus far. This helped drawing up the final version of the competence framework.

Consistent with the literature (Hsu \& Sandford, 2007), a consensus was stated to be achieved when at least $80 \%$ of the experts agreed about the formulation of a competence. After each round, the competences were classified into three groups according to consensus criteria:

- Validated (V), if at least $80 \%$ of the experts' ratings were at level 4 or higher. In this case, the competence remained unchanged.

- Minor revision (MI), if between $70 \%$ and $80 \%$ of the experts' ratings were at level 4 or higher.

- Major revision (MA), in any other case.

Data analysis was performed using SPSS ${ }^{\circledR}$ for quantitative analysis. Answers to open questions were qualitatively analysed through WeftQDA and classified into relevant categories for later examination.

\section{Results}

From the literature review, a preliminary version of the competence framework consisting of thirty-two teaching competences could be outlined, classified into twelve domains. In each round of the Delphi method, competences not meeting the consensus criteria were modified, herewith taking into account the suggestions from the experts. 
Figure 3 provides a concrete example of a competence's evolution during the consultation process.

[Figure 3 near here]

Following the three rounds, the preliminary version of the competence framework was refined and consolidated according to the experts' opinions. Based on the consensus criteria mentioned above, during the first round 16 of the 32 initial competences were validated (V), 9 competences needed minor revision (MI) and 7 competences needed major revision (MA). As a consequence of the revision process, 14 competences were reformulated, 2 competences - TK1 and TK2 - were merged (M), and 1 competence - CSO1 - was deleted (D). Three new competences (N) were added to the list in order to check their adequacy during round two (see Figure 4).

In the second round, 6 additional competences were validated and 8 competences remained under revision. Experts were almost unanimous in their opinion to incorporate the three new competences suggested during the first round.

During the third and last round, 2 extra competences were validated; 6 remained under revision: 2 minor and 4 major.

[Figure 4 near here $]^{1}$

The monitor team considered competences MPK1 and DP2 as validated with $78.3 \%$ of the consensus. As competences TLP2, CM1, LP2 and ID3 did not reach a consensus, they were classified as debatable competences. We comment on them later in the discussion section.

\footnotetext{
${ }^{1}$ Note. $\mathrm{V}=$ Validated. $\mathrm{MI}=$ Minor revision. $\mathrm{MA}=$ Major revision. $\mathrm{N}=$ New. $\mathrm{M}=$ Merged. $\mathrm{D}=$ Deleted. The proportion of the experts' ratings at level 4 or higher appear in brackets.
} 
The resulting validated framework consisted of thirty-three competences, organised into twelve different clusters describing the knowledge fields of a competent teacher (see Table 1). These competences mirror targets to be attained by all secondary mathematics student teachers. It should be borne in mind that TK1 and TK2 were merged and renamed as TK1; CSO1 was deleted.

[Table 1 near here]

\section{Discussion}

In Spain, specific competences for secondary mathematics student teachers guiding initial teacher education programmes curriculum are missing. Available frameworks are narrowly defined and had not been validated thus far. This research contributed to the identification of knowledge, skills and attributes that secondary mathematics student teachers should acquire during initial teacher education programmes to become efficient mathematics teachers. A key outcome of this study has been the development and validation of an international framework of professional competences for secondary mathematics student teachers. This framework can be used as a starting point for initial teacher education assessment.

Although changes in wording throughout the validation process were necessary, the initial version of the competence framework designed by the research team could already be considered a rational approximation of the final result. All competences seem to be in accordance with the TPACK model and Shulman's (1987) model of pedagogical reasoning and action, as largely in line with the available international frameworks. Additionally, during the consultation process, most experts pointed out the quality of the competence framework as well as its significance to teacher education and teaching practice. Experts described the framework as interesting, comprehensive, clear, 
coherent and consistent. Only two participants indicated it was excessively long and pointed out some competences could distract teachers from their core activities.

Modifications in competences were consistently evaluated and approved of by the monitor team based on their professional judgement. Only 4 competences of the 32 initially proposed, did not reflect any consensus (see Table 1). Although these competences received lower ratings during the validation process, the monitor team did not find a logical explanation for excluding them.

The first debatable competence (TLP2) is about teachers' ability to analyse and learn from their own teaching practices. Gathering evidence about the students' learning progress helps teachers to know when, how and why to employ didactical strategies to maximise the students' outcomes in mathematics. However, it seems experts in the higher secondary education mathematics domain consider this of lesser importance. This is strange given the fact research shows teachers should be trained to reflect on their own practices and stresses this competence as all-important for effective teaching (Morris, Hiebert, \& Spitzer, 2009; OECD, 2005), even in the mathematics domain (Yeh \& Santagata, 2015). But the observation is not unique. Also Black (2015) observed that mathematics teachers encounter more difficulties in this domain by stating that they see fewer alternative or creative solutions to tackle learning and teaching strategies in their classes.

The second competence - not completely validated (CM1) - is related to classroom management practices. Experts justified their low ratings by stressing this competence does not align with the job of mathematics teachers. Note herewith that (see Figure 4) a consensus benchmark was nearly reached (76.2\%). Nevertheless, our finding is in contrast to the results of other mathematics education studies that explicitly incorporated classroom management from a theoretical and practical teaching 
perspective (Schmidt et al., 2011). In the Spanish context, García-Longoria and Blanco (2005) carried out a study about trainee teachers' problems when entering the teaching profession. Up to $35 \%$ of novice teachers - including mathematics teachers - reported fearing disciplinary problems during class. In view of our findings, it is possible the experts involved in the Delphi method had adopted a too narrow and dated conception of classroom management by stressing discipline, rules and authority. Emmer and Stough (2001) clearly state classroom management goes beyond this dimension and comprises all strategies and approaches fostering a conducive learning environment to attain the learning objectives. This implies all decisions of teachers - for instance, selection of an adequate learning content, engaging learning strategies, effective organisational measures - are part of classroom management.

To discuss the third debatable competence (LP2), we return to Shulman's (1986) definition of curricular knowledge and its contribution to instructional quality (Hill \& Charalambous, 2012). Previous research agreed a focus on curriculum knowledge is often weaker in the mathematics domain, where content dominates teaching approaches (Speer, King, \& Howell, 2015).

Lastly, there is a lack of consensus in relation to the competence about inclusive education (ID3). This raises concerns. Nevertheless, our results are in line with previous findings pointing out middle- and high-school mathematics teachers and pre-service teachers have limited understanding of students' educational needs in an inclusive setting and that teacher education hardly helps preparing them meeting specific mathematics learning needs (Van Reusen, Shoho, \& Barker, 2000). However, an absence of sustained experiences during initial teacher education may weaken student teachers' attitudes towards inclusion and diversity (Sosu, Mtika, \& Colucci-Gray, 2010). Inclusion and coping with diversity build on competences that belong to an 
interrelated cyclic process: identifying students with specific educational needs (ID1), cooperating with specialised supporting staff to seek advice about students with specific educational needs (ID3), and adapting teaching in view of students' needs (ID2). It is expected from teachers to seek the support of specially trained staff, in order to adequately assist students with special educational needs. This competence also aligns with PC2, since both refer to the ability to work effectively with colleagues (Van Reusen, Shoho, \& Barker, 2000). Especially because of its key position in the cyclic process, the monitor team still considers this competence as relevant to be included in the final version of the competence framework.

Some implications and directions for future research can be linked to the results of this study. Our validated competence framework contributes to analyse the extent to which these competences are actually attained/pursued in Spanish initial teacher education programmes. To that end, a new study will be set up involving a sample of student teachers, teacher educators, mentors supporting field experiences in secondary education schools, and recently graduated teachers from initial secondary mathematics teacher education programmes. This will help to establish benchmarks to discuss the quality of mathematics teacher education and study the adoption in practice of the four datable competences within the Spanish context.

Some limitations have to be discussed. For instance, the competence framework does yet not include benchmark information specifying mastery levels in regard of prospective or in-service teachers' assessment. The lack of such benchmarks is a common international feature. In few countries, comprehensive benchmark frameworks have been established in order to determine the extent to which teaching competences should be mastered (Erebus International, 2008; Quality Assurance Agency for Higher Education, 2000). As suggested above, a benchmark study can now be set up to 
examine the current mastery level in the Spanish teacher education setting. This study can help to reveal which competences are pursued and attained at a critical level in initial teacher education programmes in Spain. Special attention must be paid to the four debatable competences. These findings could additionally help to define support trajectories to mentor starting teachers in view of critical competences mastered below a predefined level. The development and mastery of certain competences needs to be regarded as a lifelong endeavour (European Commission, 2013; Morris, Hiebert, \& Spitzer, 2009).

A second limitation builds on the fact teaching practices depend on particular educational contexts. In this sense, the present competence framework reflects priorities outlined for secondary mathematics student teachers in Spain. Nevertheless, it may serve as a starting point for the international educational research in view of developing teaching competence frameworks within other specific national or regional contexts.

To conclude, attracting, developing and retaining effective teachers is vital for any educational system aiming at improving student learning outcomes (OECD, 2005). This situation especially applies to the Spanish context, where teachers work in increasingly complex settings. Therefore, it is vital to strengthen initial teacher education programmes, starting from this framework of newly validated teaching competences to ensure high-quality trained prospective teachers.

\section{Acknowledgements}

The authors wish to thank all the experts who participated in the study for their collaboration, effort and perseverance during the development of the competence framework. Their opinions and suggestions as experts were very useful to validate our initial proposal. In addition, their participation was a key factor in order to achieve the minimum sample size needed for a Delphi method. 


\section{References}

Alake-Tuenter, E., Biemans, H., Tobi, H., \& Mulder, M. (2013). Inquiry-based science teaching competence of primary school teachers: A Delphi study. Teaching and Teacher Education, 35, 13-24.

Australian Association of Mathematics Teachers. (2006). Standards for excellence in teaching mathematics in Australian schools. Retrieved April 13, 2016, from http://www.aamt.edu.au/Better-teaching/Standards/Standards-document

Baumert, J., \& Kunter, M. (2006). The COACTIV Model of Teachers' Professional Competence. In M. Kunter, J. Baumert, W. Blum, U. Klusmann, S. Krauss, \& M. Neubrand (eds.). Cognitive Activation in the Mathematics Classroom and Professional Competence of Teachers (pp. 25-48). New York: Springer US.

Black, G. L. (2015). Developing Teacher Candidates' Self-Efficacy through Reflection and Supervising Teacher Support. In Education, 21(1), 78-98.

Comisión de Educación de CEMAT. (2011). Conclusiones del seminario CEMat 2010: Un año de experiencia en la especialidad de matemáticas del Máster de Profesor de Secundaria: Evaluar y tomar decisiones [Conclusions of the CEMAT 2010 seminar: A year of experience in the specialty of mathematics of the Master Degree in Teacher Training: Evaluating and making decisions]. La Gaceta de La RSME, 14(1), 65-68.

Dalziel, J. \& Dobozy, E. (2016). The complementary nature of learning design and TPACK. In: Dalziel, J. (Eds.). Learning Design: Conceptualizing a Framework for Teaching and Learning Online. New York: Routledge, pp. 96-116.

Department for Education. (2011). Teachers' standards. Retrieved June 26, 2016 from https://www.gov.uk/government/publications/teachers-standards

Doering, A., Veletsianos, G., Scharber, C., \& Miller, C. (2009). Using the Technological, Pedagogical, and Content Knowledge framework to design online learning environments and professional development. Journal of Educational Computing Research, 41(3), 319-346. 
Emmer, E. T., \& Stough, L. M. (2001). Classroom management: A critical part of educational psychology, with implications for teacher education. Educational psychologist, 36(2), $103-112$.

Erebus International. (2008). Scoping study on the development of teaching standards in the broader Asia-Pacific Region. Australia: Department of Education, Employment and Workplace Relations.

European Commission. (2013). Supporting Teacher Competence Development for Better Learning Outcomes. Brussels: EC.

García-Longoria, M., \& Blanco, L. (2005). La formación inicial de los profesores de matemáticas: Una encuesta entre los profesores de Secundaria [Initial teacher education of mathematics teachers: A survey on secondary teachers]. Campo abierto, 28, 111-128.

General Teaching Council for Northern Ireland. (2011). Teaching: the Reflecting Profession, Retrieved October 19, 2016, from http://www.gtcni.org.uk/userfiles/file/The_Reflective_Profession_3rd-edition.pdf

General Teaching Council for Scotland. (2012). The Standards for Registration: mandatory requirements for Registration with the General Teaching Council for Scotland. Retrieved June 26, 2016 from http://www.gtcs.org.uk/web/FILES/thestandards/standards-for-registration-1212.pdf

Green, R. A. (2014). The Delphi Technique in Educational Research. SAGE Open, 4(2).

Hansen, A., Mavrikis, M., \& Geraniou, E. (2016). Supporting teachers' technological pedagogical content knowledge of fractions through co-designing a virtual manipulative. Journal of Mathematics Teacher Education, 19(2), 205-226.

Hill, H. C., Ball, D. L., \& Schilling, S. G. (2008). Unpacking Pedagogical Content Knowledge: Conceptualizing and Measuring Teachers' Topic-Specific Knowledge of Students. Journal for Research in Mathematics Education, 39(4), 372-400.

Hill, H. C., Rowan, B., \& Ball, D. L. (2005). Effects of Teachers' Mathematical Knowledge for Teaching on Student Achievement. American Educational Research Journal, 42(2), $371-406$. 
Hill, H. C., \& Charalambous, C. Y. (2012). Teacher knowledge, curriculum materials, and quality of instruction: Lessons learned and open issues. Journal of Curriculum Studies, 44(4), 559-576.

Hsu, C. C., \& Sandford, B. A. (2007). The Delphi technique: Making sense of consensus. Practical Assessment, Research \& Evaluation, 12(10), 1-8.

International Society for Technology in Education. (2008). ISTE Standards for teachers. Retrieved April 13, 2016, from http://www.iste.org/standards/iste-standards/standardsfor-teachers

Kimmons, R. (2015). Examining TPACK's theoretical future. Journal of Technology and Teacher Education, 23(1), 53-77.

Kleinhenz, E., \& Ingvarson, L. (2007). Standards for teaching: Theoretical underpinnings and applications. Retrieved April 13, 2016, from http://research.acer.edu.au/teaching_standards/1/

Koster, B., Brekelmans, M., Korthagen, F., \& Wubbels, T. (2005). Quality requirements for teacher educators. Teaching and Teacher Education, 21, 157-176.

Linstone, H. A., \& Turoff, M. (1975). The Delphi method: Techniques and applications. Cambridge, MA: Addison-Wesley.

Lohmar, B., \& Eckhardt, T. (2013). The Education System in the Federal Republic of Germany 2011/2012. Bonn: Secretariat of the Standing Conference of the Ministers of Education and Cultural Affairs.

Ministerio de Educación y Ciencia. (2007). Orden ECI/3858/2007, de 27 de diciembre, por la que se establecen los requisitos para la verificación de los títulos universitarios oficiales que habiliten para el ejercicio de las profesiones de Profesor de Educación Secundaria Obligatoria y Bachillerato [Order ECI/3858/2007, dated 27 December, establishing the requirements for the verification of university official degrees which enable for the profession as a teacher at secondary education, vocational training and language teaching training]. Boletín Oficial del Estado, 312, 53751-53753. 
Mishra, P., \& Koehler, M. J. (2006). Technological Pedagogical Content Knowledge: A framework for teacher knowledge. Teacher College Record, 108(6), 1017-1054.

Morris, A. K., Hiebert, J., \& Spitzer, S. M. (2009). Mathematical knowledge for teaching in planning and evaluation instruction: What can preservice teachers learn? Journal for Research in Mathematics Education, 40(5), 491-529.

Muñiz-Rodríguez, L., Alonso, P., Rodríguez-Muñiz, L. J., \& Valcke, M. (2016). ¿Hay un vacío en la formación inicial del profesorado de matemáticas de Secundaria en España respecto a otros países? [Is there a gap in initial secondary mathematics teacher education in Spain compared to other countries?]. Revista de Educación, 372, 111-140.

National Council for Accreditation of Teacher Education. (2008). Professional standards for the accreditation of teacher preparation institutions. Washington.

National Council of Teachers of Mathematics. (2012). NCTM CAEP Standards. Retrieved April 13, 2016, from http://www.nctm.org/uploadedFiles/Standards_and_Positions/CAEP_Standards/NCTM \%20CAEP\%20Standards\%202012\%20-\%20Secondary.pdf

OECD. (2005). Teachers matter: Attracting, developing and retaining effective teachers. Paris: OECD.

Papanikolaou, K., Gouli, E., \& Makri, K. (2014). Designing Pre-service Teacher Training based on a Combination of TPACK and Communities of Inquiry. Procedia - Social and Behavioral Sciences, 116, 3437-3442.

Parveva, T., Noorani, S., Ranguelov, S., Motiejunaite, A., \& Kerpanova, V. (2011). Mathematics Education in Europe: Common Challenges and National Policies. Brussels: Education, Audiovisual and Culture Executive Agency.

Reynolds, M. (1999). Standards and Professional Practice: The TTA and Initial Teacher Training. British Journal of Educational Studies, 47(3), 247-260.

Santos, M. A., \& Lorenzo, M. (2015). La formación del profesorado de Educación Secundaria: pensando en la reconstrucción del proyecto universitario [Teacher training at secondary 
education: Thinking about rebuilding the university project]. Revista Española de Pedagogía, 73(261), 479-492.

Schmidt, W. H., Blömeke, S., Tatto, M. T., Hsieh, F. J., Cogan, L., Houang, R. T., \& Schwille, J. (2011). Teacher education matters: A study of middle school mathematics teacher preparation in six countries. New York, NY: Teachers College Press, Columbia University.

Shulman, L. (1986). Those who understand: knowledge growth in teaching. Educational Researcher, 15(2), 4-14.

Shulman, L. (1987). Knowledge and teaching: Foundations of the new reforms. Harvard Educational Review, 57(1), 1-22.

Smith, K. S. \& Simpson, R. D. (1995). Validating teaching competencies for faculty members in higher education: a national study using the Delphi method. Innovative Higher Education, 19(3), 223-234.

Speer, N. M., King, K. D., \& Howell, H. (2015). Definitions of mathematical knowledge for teaching: using these constructs in research on secondary and college mathematics teachers. Journal of Mathematics Teacher Education, 18(2), 105-122.

Sosu, E. M., Mtika, P., \& Colucci-Gray, L. (2010). Does initial teacher education make a difference? The impact of teacher preparation on student teachers' attitudes towards educational inclusion. Journal of Education for Teaching, 36(4), 389-405.

Tang, S. Y. F., Cheng, M. M. H., \& Wong, A. K. Y. (2016). The preparation of pre-service student teachers' competence to work in school. Journal of Education for Teaching, 42(2), 149-162.

Van Reusen, A. K., Shoho, A. R., \& Barker, K. S. (2000). High school teacher attitudes toward inclusion. The High School Journal, 84(2), 7-20.

Volman, M. (2005). A variety of roles for a new type of teacher educational technology and the teaching profession. Teaching and Teacher Education, 21, 15-31.

Welsh Government. (2011). Revised professional standards for education practitioners in Wales. Retrieved October 19, 2016, from 
http://learning.gov.wales/docs/learningwales/publications/140630-revised-professionalstandards-en.pdf

Wu, N. (2014). The implementation of the National Professional Standard for K-12 Teachers, 2012 (NPST) at regional and local level in China: A case study of regional teacher professional development standards implementation in Qingyang District, Chengdu, China. Higher Education of Social Science, 7(3), 1-11.

Yeh, C., \& Santagata, R. (2015). Preservice teachers' learning to generate evidence-based hypotheses about the impact of mathematics teaching on learning. Journal of Teacher Education, 66(1), 21-34. 
Table 1. Validated competence framework for initial teacher education programmes in mathematics.

\section{Mathematical content knowledge.}

MCK1. Know and understand mathematical concepts, ideas, theories and procedures according to different mathematical branches such as calculus, algebra, geometry, discrete mathematics, statistics and probability, and measurement.

MCK2. Know the history and recent findings of mathematics to convey a dynamic mathematical perspective.

\section{Mathematical pedagogical knowledge.}

MPK1. Identify students' background and prior mathematical knowledge, as well as difficulties and mistakes, and apply those processes that can help students to face and solve them.

MPK2. Communicate and represent mathematical thinking coherently and clearly both orally and in writing.

MPK3. Make connections between mathematical concepts and other subject areas and real life problems.

MPK4. Know relevant findings from teaching mathematics research as guidance for professional practice in the classroom.

\section{Teaching and learning processes.}

TLP1. Select creative and innovative strategies for teaching and learning mathematics appropriate to students' needs.

TLP2. Be able to explain the impact on students of the strategies adopted for mathematical learning.

TLP3. Use a wide variety of materials and resources, such as games, puzzles, riddles, and technological devices, for teaching and learning mathematics.

TLP4. Know resources for mathematics teachers, such as mathematical research journals, professional mathematics organisations web sites, among others.

\section{Classroom management.}

CM1. Enforce rules and routines of behaviour in classroom practice during mathematics lessons, in accordance with the school behaviour policy. ${ }^{*}$

CM2. Use a variety of techniques to motivate students to develop enthusiasm for and interest in mathematics.

CM3. Make efficient use of classroom space to accommodate different learning techniques both collaboratively and individually.

CM4. Promote mathematical learning situations that allow students to ask questions themselves, investigate, and seek answers.

\section{Lesson planning.}

LP1. Plan well-structured lessons that address appropriate learning goals, considering national mathematics curricula standards.

LP2. Know the curriculum framework in force in Spain, identify its different elements and its application in the area of mathematics in secondary education.

LP3. Set homework and plan other out-of-class activities to reinforce the mathematical knowledge that students have previously acquired. 
Assessment and mentoring.

AM1. Employ different methods and techniques to assess students' mathematical learning that are rigorous, objective and fair.

AM2. Use the results obtained from the assessment to diagnose difficulties, set goals and plan future learning experiences within the area of mathematics.

AM3. Provide constructive, purposeful and timely feedback to students, their families, and school authorities.

Developmental psychology.

DP1. Know student characteristics (e.g., motivation, attitudes...) and their social context.

DP2. Know the stages of student cognitive development and its influence on mathematics learning.

DP3. Adapt the teaching process to support students' learning at different stages of development using adequate strategies and methods.

Inclusion and diversity.

ID1. Identify different student needs, including those with special educational needs, high ability, and/or disabilities.

ID2. Adapt teaching to respond to the strengths and needs of all students, designing differentiated instruction that addresses student diversity and encouraging an inclusive education.

ID3. Know when and about which aspects to seek support and to cooperate with specialised supporting staff for students with specific educational needs."

Technology knowledge.

TK1. Apply information and communication technologies within educational settings and mathematics teaching, analysing its impact on mathematics learning.

\section{Communication skills.}

CS1. Use effective verbal and nonverbal communication techniques to foster and support interaction in the classroom and in the school community.

\section{Contribution to school organisation.}

CSO2. Contribute in the design of the comprehensive education plan and common school activities with special attention to teaching quality improvement.

CSO3. Participate actively in school decision making, especially in those that apply to the mathematics department.

\section{Personal commitment.}

PC1. Exhibit personal attributes - such as enthusiasm for mathematics and its learning, care and respect for the students, autonomy, self-esteem - that assist to engage students in their learning and maximize their achievement.

PC2. Contribute to the improvement of mathematics teaching by actively engaging students and collaborating with colleagues in mathematical activities both inside and outside the classroom.

PC3. Commit to teaching professional development, participating in training programmes for mathematics teachers.

Note. Debatable competences are printed in italics. 
Figure 1. TPACK model (reproduced with permission of the publisher, (C) 2012 by tpack.org).

Figure 2. The model of pedagogical reasoning and action. Adapted from Shulman (1987).

Figure 3. Example of how a competence evolved during the Delphi method.

Figure 4. Results from the validation process. 